\title{
La comunidad en cuestión. Un episodio de la historia moral del teatro, según Rousseau
}

Alicia Ma de Mingo Rodríguez Universidad de Sevilla

Resumen

El modelo de comunidad que diseña Rousseau, ya a partir de sus Discursos de la década de 1750, exigía que la propuesta ilustrada de D'Alembert para que hubiese un teatro estable en Ginebra fuese rechazada por Rousseau, con multitud de variados argumentos, en su Carta a D'Alembert sobre los espectáculos (1758), de una extraordinaria densidad historiográfica. Es necesario, sin embargo, no desatender lo esencial de la crítica de Rousseau, que él mismo embrolla, y situar la crítica al teatro en un terreno sobre todo simbólico, en tanto representa el arte sistemático de la simulación, la falsedad y el vivir disipadamente las vidas de otros, lo que apartaría a la persona y a la comunidad de la honestidad y sinceridad (autenticidad) que son imprescindibles a la transparencia como conditio sine qua non de la comunidad.

Palabras clave: Rousseau, D'Alembert, comunidad, transparencia, moral, teatro. 


\section{Abstract}

Community's model designed by J.-J. Rousseau, already from his Discourses of the decade of 1750, demanded that the Enlightened proposal of D'Alembert so that there was a permanent theater in Geneva was rejected by Rousseau with many different arguments in his extraordinary dense (from a historiographical point of view) Letter to M. D'Alembert on spectacles (1758). It is necessary, nevertheless, not to disregard the essence of Rousseau's critique, which he itself complicates, and to place the critique to the Theatre in a mainly symbolic dimension, as the Theater represents the sistematic art of simulation, falsehood and living lives of others very carefreely. In this case, it would separate the Person and the Community from honesty and sincerity (authenticity), that are essentials to Transparency as conditio sine qua non of Community.

Keywords: Rousseau, D'Alembert, Community, Transparency, Moral, Theater.

\section{El dilema de Ser y Parecer}

$\mathrm{O}$ ponerse al "espíritu de la época" no es una posibilidad al alcance de cualquiera, pues casi siempre comporta un coste demasiado alto para ser soportado por quien carece de suficiente convicción íntima, muy bien pertrechada de argumentos, y sobrada entereza moral. Son muy pocos los capaces de mantenerse indemnes frente a los embates que convicción y entereza habrán de sufrir, entre estos, ser tildado de marginal, loco o incluso misántropo, como le ocurrió al propio Rousseau. Además, el riesgo no sólo sería exterior. Reducido a su propio aislamiento, a ser un "paseante solitario", se estaría expuesto a caer, por mor de la "autenticidad", en una especie de cierre de la mente e incluso en un fanatismo alarmante. Algo de todo ello sabía, desde luego, Jean- 
Jacques Rousseau, y lo supo desde muy pronto, de inmediato que osó enfrentarse reiteradamente a un siglo tan -en cierto modofanático como el suyo, y sobradamente engalanado con su propio narcicismo. Los dos Discursos que escribió para la Academia de Dijon en 1750 y 1754-1755 (el Discurso sobre las Ciencias y las Artes y el Discurso sobre el origen y los fundamentos de la desigualdad entre los hombres, respectivamente) prueban que Rousseau no temía el enfrentamiento, aunque, como él mismo habría de confesar, nunca creyó que llegara a tener que pagar tan elevado precio vital. En un siglo que enarboló con entusiasmo la idea de progreso, Rousseau se negó a admitir sin más que el desarrollo de las artes y de las ciencias llevase consigo, necesariamente, un progreso moral en los seres humanos. Y no carece de importancia, sin duda, que fuese una especie de tribunal moral (no social, ni científico, ni revolucionario, etc.) el que en el caso del "aguafiestas" Rousseau hubiese de decidir sobre el progreso. Sus ideas eran tan "a la contra" que -el episodio es bien conocido- Voltaire le escribió que tras leer su Discurso le entraban a uno ganas de ponerse a cuatro patas... ${ }^{1}$

Quizás el aspecto más definitivo en el breve ensayo que aquí propongo sea -a título de presentación- considerar en qué medida no ya las artes y las ciencias, en general, sino específicamente el teatro, en su necesario vínculo con la comunidad, forzosamente tenía que sucumbir en la estimativa russoniana, una vez fijado el

${ }^{1}$ En un pasaje memorable, en efecto, Voltaire había escrito a Rousseau: "He recibido, señor, vuesto libro contra el género humano; os lo agradezco. Complaceréis a los hombres a quienes cantáis sus verdades, pero no los corregiréis. Pintáis con colores muy verdaderos los horrores de la sociedad humana cuya ignorancia y debilidad prometen tantas dulzuras. No se ha empleado tanto talento nunca en intentar tornarnos bestias. Dan ganas de caminar a cuatro patas cuando se lee vuestra obra; sin embargo, como hace más de sesenta años que he perdido ese hábito, siento desdichadamente que me es imposible reencontrarlo" (Voltaire, 1977: 273). Rousseau respondió, por supuesto, con observaciones de esta guisa, insoportables a la sensibilidad de la época: "Jamás he visto tantos necios. El teatro hormiguea de ellos, los cafés relucen con sus sentencias; alardean en los diarios, las calles están cubiertas de sus escritos" (Rousseau, 1977: 278). 
horizonte de su crítica cultural, en la medida en que para Rousseau el teatro estimularía, refinándola y prestigiándola con los oropeles de la alta cultura, una de las más perniciosas escisiones que podría sufrir la comunidad verdadera. Me referiré a ello en breve. En uno de los flancos de la crítica de Rousseau, sigue perfectamente vigente la censura tradicional a un teatro que no ofreciese en sus representaciones un panorama moral realmente edificante. En este sentido, la crítica de Rousseau no es novedosa. Tampoco lo es por lo que se refiere al modo en que, con desprecio y múltiples recelos, Rousseau prosigue el ataque común a la vida licenciosa de los actores, en la que ve alzarse un ejemplo muy pernicioso para la sociedad en su conjunto.

Creo, entonces, que es más interesante otra posibilidad crítica. En concordancia con su época (mediados del XVIII), y ya como prerromántico, Rousseau es muy sensible a la problemática de la subjetividad y, no menos, a la de una comunidad que tendría que encontrar su propio camino de expresión, honestidad y unidad, justo en la medida en que pudiese conjurar la amenaza de una mascarada individual y/o colectiva. Para eso se haría necesario - pensaba Rousseau- desactivar el excesivo prestigio concedido al teatro. La comunidad es comunidad de personas, y es preciso preservar una base o fondo de autenticidad, en primer lugar, simbólicamente. Mientras que quienes preconizaban los valores más aparentemente positivos del teatro (en la Carta serían D'Alembert y, al fondo, Voltaire) valoraban su potencial moral y social edificante, pues sería capaz de transmitir valores y convertir a los espectadores en más sabios y refinados, más solidarios y humanos, Rousseau, sin embargo, se desvía hacia una cuestión mucho más formal, relativa a la alienación del ser personal y, a resultas de ello, de la comunidad. En definitiva, se trataba de la grave escisión entre ser y parecer, en la medida en que éste fuese capaz de engullir a aquél ( $C f r$. Starobinski, 1983: 11 y ss.) y generar un auténtico culto a las apariencias, 
lo que redundaría en una enorme incertidumbre en las relaciones sociales y en una desconfianza adornada de buenos modales, e incluso una especie de peligrosa distorsión en el ser personal. El "escenario de pesadilla" de Rousseau -si se pudiera formular en estos términos- tiene forma de preguntas como: ¿qué ocurriría si la figura humana y profesional del actor, haciendo gala de su másca$r a$, se convirtiese en modelo a imitar? ¿Y si la máscara no fuese sólo un medio externo, sino que acabara por ocupar la zona de verdad e interioridad reservada a la persona?

La Carta que escribe Rousseau a D'Alembert cobra sentido en tanto podamos comprender cómo todos los fantasmas se concentran, para Rousseau, en la idea diabólica de un teatro estable, es decir, a disposición continua de la comunidad. ¿Cómo podía estar de acuerdo él, que ya en 1750, ocho antes, en el primero de sus discursos había criticado duramente la capacidad de los seres humanos (y especialmente los de su siglo) para el cultivo de las apariencias y la mascarada? ¿Cómo podía estar de acuerdo él, que llegaba a defender una rusticidad bien avenida con la naturalidad que pudiese actuar como cortafuegos contra la artificialidad de las apariencias falsas y, digamos, meramente "corteses" (con toda su parafernalia: la "continencia exterior", la "decencia", el "civismo" uniformizador, la "conveniencia")? ¿Cómo podría afianzarse la virtud en medio de una gran mascarada, de modo que la pose "exterior" de las costumbres dejase de responder a la naturalidad del "interior", tornándose todos los conciudadanos impenetrables y desconfiados unos para otros, y en un escenario de posible engaño y traición de todos contra todos? En efecto, ya en su Discurso de 1750 Rousseau se había lamentado de que

nadie se atreve ya a parecer lo que es y, en esta perpetua compulsión, los hombres que forman este rebaño que se llama sociedad, puestos en las mismas circunstancias, harían siempre las mismas 
cosas si motivos más poderosos no se lo impidiesen. Nunca se sabrá bien con quién se negocia [...]

¡Qué cortejo de vicios no acompañará esta incertidumbre! No más amistades sinceras, más verdadera estima, más confianza fundada. Las sospechas, las sombras, los temores, la frialdad, la reserva, el odio, la traición se ocultarán sin cesar bajo ese velo uniforme y pérfido del civismo, bajo esa urbanidad tan alabada que debemos a las luces de nuestro siglo (Rousseau, 1977: 41).

Si ya la sociedad potencia esa corrupción del ser por el parecer, el problema añadido que plantean las artes es que ofrecen medios ingeniosos y artificios abundantes para refinar dicha corrupción. Si un habitante de continentes lejanos quisiera conocernos a partir de lo que parecemos, dice Rousseau, nos conocería justamente por lo contrario de lo que en verdad somos (Rousseau, 1977: 42-43). A mediados del XVIII, el ataque al glamour y rutilancia de les lumières estaba servido. Y Rousseau, en verdad, no estaba solo en semejante empresa. ¿No edita, en 1782, Pierre Choderlos de Laclos, con gran éxito, Les liaisons dangereuses? ¿Valmont y la perspicaz y maquiavélica marquesa de Merteuil no apoyaban la feroz crítica russoniana? En realidad, el malestar procedía desde la época de Molière. Como recuerda Starobinski,

en 1748 el tema de la falsedad de las apariencias no tiene nada de original. En el teatro, en la iglesia, en las novelas, en los periódicos, cada uno a su modo, denuncia los falsos pretextos, las convenciones, las hipocresías, las máscaras. En el vocabulario de la polémica y de la sátira no hay términos que aparezcan más a menudo que descubrir y desenmascarar. El Tartuffe ha sido leído una y otra vez. El pérfido, el "vil adulador" y el bribón disfrazado se encuentran en todas las comedias y en todas las tragedias. En el desenlace de una intriga bien llevada, hacen falta traidores ocultos. Rousseau (Jean-Baptiste) permanecerá en la memoria de los 
hombres por haber escrito: "Cae la máscara, el hombre queda / Y el héroe se desvanece" (Starobinski, 1983: 12).

A quien desde el principio de su trayectoria como pensador, con treinta y ocho años, tanto empeño había puesto en el desenmascaramiento no podía serle indiferente que se quisiera: 1) entronizar simbólicamente, no sólo realmente -aunque Rousseau no lo dice con tanta claridad- el teatro como arte por antonomasia que, a su juicio, practica, aplaude y consagra la mascarada; pretendiendo, además, 2) convertirlo en santo, seña y emblema del prestigio, formación y "altura" de Ginebra; y 3) aduciendo argumentos falaces, ingenuos (D'Alembert) y claramente "interesados", como piensa Rousseau que son los argumentos esgrimidos por D'Alembert, tras los que se ocultaría sobre todo Voltaire, a la sazón vecino de Ginebra desde 1755 (Gouhier, 1983: 111 y ss.), donde se había refugiado después de salir huyendo de Alemania y ante la imposibilidad de ser acogido en Francia. La polémica estaba servida. La Carta va a mostrar toda la batería de argumentos, algunos más razonables que otros, que Rousseau va a esgrimir contra el teatro y a favor de su Ginebra. Si en esa defensa hubiera que sostener con entereza una posición que hoy, en algún sentido, llamaríamos contracultural, no era precisamente a Jean-Jacques Rousseau a quien habría de importarle; por el contrario, le complacería.

\section{La Carta a D'Alembert sobre los espectáculos}

La circunstancia concreta era ésta: en noviembre de 1757 había aparecido en el volumen II de la Enciclopedie un artículo de D’Alembert sobre Ginebra (D'Alembert, 1967), en el que recomendaba la presencia de una compañía estable de teatro para la ciudad. Según su argumentación, los ginebrinos rechazaban los espectáculos no como tales ni en general, sino porque temían la di- 
sipación y el libertinaje que los comediantes acabarían por expandir entre la juventud. D'Alembert, sin embargo, pensaba que ello podría remediarse con leyes severas sobre las costumbres de dichos comediantes, de modo que Ginebra podría tener su teatro estable. Así, "las representaciones teatrales formarían el gusto de los ciudadanos, dándoles fineza de tacto y una delicadeza de sentimiento que es muy difícil alcanzar sin ese recurso" (D’Alembert, 1967: 417). Seguía criticando D’Alembert el prejuicio "bárbaro" acerca del envilecimiento propio de los actores (tan necesarios al progreso y al sostén de las artes), que habría contribuido al desarreglo que se les reprochaba, pues los actores -argumentaba- pretenden indemnizar con placeres la estima que se les niega. Sin embargo, era posible encontrar una solución a este problema, pudiéndose convertir la troupe de actores de la compañía estable de Ginebra en la mejor de Europa, atrayendo el teatro a nuevos visitantes. Ginebra dejaría de ser la ciudad triste que los franceses consideraban que era (D’Alembert, 1967: 418) para convertirse en una ciudad para disfrutar de placeres honestos. Dejándose llevar por el entusiasmo, D’Alembert pensaba que Ginebra podría, incluso, encabezar esta nueva revolución del teatro y servir de modelo a otras ciudades europeas. Sin ser objeto de anatema, a los actores ya no se les excomulgaría ni se les trataría con desprecio. De este modo, "una pequeña república tendría la gloria de haber reformado a Europa sobre este tema, más importante quizás de lo que se piensa" (D’Alembert, 1967: 418).

Rousseau, sin embargo, había sido informado por Diderot del contenido de esta propuesta, y estaba ansioso por leer el artículo de D’Alembert. Éste debería haberse figurado que, ciertamente, para el ciudadano Rousseau por supuesto que "el tema" era más importante de lo que podría creerse (¡mucho más, incluso, que para el aburrido -en Ginebra- Voltaire!), y que no estaría dispuesto a pasarlo por alto. Para él no se trataba de un asunto "artístico". 
Ante todo, era su Ginebra la que estaba en juego, su ciudad -la de su infancia ${ }^{2}$ - la que se exponía nada más y nada menos que casi a perder su alma. Tal es el tono dramático de la crítica russoniana. Ni debía haber semejante compañía estable ni, mucho menos aún, había de elegirse a Ginebra como "conejillo de indias" para arriesgados experimentos culturales... Ni qué decir de que el propio D'Alembert, cuando leyó la extensa Carta de Rousseau, se vio obligado a responderle (D'Alembert, 1967: 432-458).

En principio, la Carta a D'Alembert sobre los espectáculos podría ser tenida por un escrito menor o muy "circunstancial" del autor de los Discursos, La Nueva Heloise, el Emilio o El contrato social, entre otras obras destacadas -aunque, según el propio Rousseau, había sido uno de los escritos que más le había complacido escribir-. ${ }^{3}$

${ }^{2}$ Cfr. La extensa nota a pie de página que introduce Rousseau al final de su Carta (1994: 168-169).

${ }^{3}$ Tras relatar las penosas circunstancias en que debió escribir su Carta, Rousseau narra sus propias impresiones respecto a la obra, en estos términos: "Fue ése [...] el primero de mis escritos en que haya encontrado placer en el trabajo. Hasta entonces, la indignación de la virtud me había servido de Apolo, pero esta vez me inspiraron la ternura y la serenidad de alma. Me habían irritado las injusticias de las que sólo había sido espectador; aquellas de las que había sido víctima me entristecieron, y esta tristeza sin hiel no era más que la de un corazón demasiado amante, demasiado tierno, que, engañado por aquellos a quienes había creído de su temple, se veía forzado a replegarse en su interior. Guiado por cuanto acababa de ocurrirme, conmovido todavía por tantos movimientos violentos, el mío mezclaba el sentimiento de sus penas a las ideas que había provocado en mí la reflexión sobre aquella materia: mi trabajo se resintió por esa mezcla [...]. A todo esto se mezclaba cierto enternecimiento por mí mismo, por sentirme morir y creer que me despedía del público" (Rousseau, 1997: 602-603). Más adelante sostiene que la Carta "respiraba una serenidad de alma que se comprendía que no era fingida. Si en mi retiro hubiese estado roído por el malhumor, mi tono se habría resentido. Reinaba en todos los escritos que había compuesto en París, pero desaparecía en la primera obra que había escrito en el campo. Para quienes saben ver, tal observación era decisiva. Se vio que había vuelto a mi elemento" (Ibid.: 609-610). Es interesante tomar en consideración el estado anímico de Rousseau y su progresivo apartamiento de la vida mundana. Lo reitera sin cesar, manifestando su satisfacción por poder abandonar la vida ostentosa y falsa, y disfrutar de su nueva libertad. Por ejemplo, refiriéndose a una época inmediatamente 
Sin embargo, prosiguiendo la línea crítica abierta por los Discursos, la Carta ofrece interesantes posibilidades de cara no ya sólo a valorar las ideas del filósofo ginebrino, su atrevido radicalismo y su acendrado punto de vista, en ocasiones hipercrítico, sino también lo que sería un episodio notable de lo que podríamos considerar la historia moral del teatro, y, en general, del panorama cultural de la Ilustración en una de sus zonas esquivas, turbias, dudosas y autocríticas, más numerosas de lo que se piensa en ocasiones.

Sin duda, la Carta a D'Alembert de Rousseau presenta una extraordinaria complejidad en sus posibles lecturas, no ya sólo por la densidad textual e historiográfica de la misma, sino también por los diversos frentes que aborda en ella, articulando arriesgadamente reflexión y polémica. Habría que valorar detalladamente, así pues, la circunstancia de todos los implicados, que eran numerosos. ${ }^{4}$ D’Alembert representaba sólo el más inmediato de los interlocutores. Respecto a Voltaire, se podría sospechar si no ya del odio, sí tal vez de los celos y, con total seguridad, del temor que podría haber infundido a Rousseau su presencia en Ginebra (Gouhier, 1983).

Comprenderíamos mejor la Carta, como documento histórico, si saliésemos de los argumentos mismos (a los que, sin embargo, ya lo aviso, habremos de atenernos aquí), orientándonos más hermenéuticamente a la circunstancia. No es de extrañar, a pesar de todo, que a la vista de la riqueza historiográfica, los comenta-

posterior a la publicación de Julie, dice Rousseau (y lo traigo a colación porque es muy sintomático), "desde hacía algún tiempo estaba dándole vueltas al proyecto de dejar por completo la literatura y sobre todo el oficio de autor. Cuanto acababa de ocurrirme me había asqueado absolutamente de las gentes de letras, y me había dado cuenta de que era imposible seguir la misma carrera sin mantener algunas relaciones con ellos. No estaba menos asqueado de las gentes de la buena sociedad y, en general, de la vida mixta que estaba llevando, una mitad conmigo mismo y otra mitad con grupos de personas para las que no estaba hecho" (Ibid.: 624).

${ }^{4}$ Todos los detalles los ofrece Gouhier (1983: 109-126). 
rios genuinamente filosóficos sobre el contenido de la Lettre no abunden en la bibliografía secundaria. Sin embargo, es necesario acercarse al texto de Rousseau con el ánimo de dejarse instruir por la polémica que le obsesionaba, atravesando el marasmo de opiniones y observaciones de Rousseau de escaso valor filosófico aunque sí, quizás, de relevancia erudita. Y, por supuesto, remontando las "ocurrencias" de un Rousseau a cuya sensatez parece que, por momentos, el aislamiento de la sociedad y su propio fanatismo le estuviesen pasando alguna factura. Advierto ya que me dirijo en este artículo a Rousseau con el ánimo de "simpatizar" hasta donde nos fuese posible con su estilo de crítica cultural, en la medida en que hoy Rousseau sería un ejemplo de osadía crítica y de "resistencia" respecto a un tema crucial, personalista para más señas, del que estimo que no deberíamos prescindir. Hay que expurgar la Carta desde nuestra contemporaneidad dejando a un lado lo pintoresco de algunas de las opiniones relativas, por ejemplo, a las actrices y el amor, o a la defensa a ultranza de la rusticidad, hoy apenas aprovechables, de un Rousseau que parece utilizar la carta a modo de ejercicio de cura psicoterapéutica contra París y sus frivolidades.

\section{El teatro bajo sospecha}

No intentaré resumir aquí, desde luego, el contenido de la Carta. Quisiera más bien destacar sólo algunas de las objeciones esgrimidas por Rousseau contra la propuesta de un teatro y compañía estables para Ginebra. No se entendería la Carta si no se valorase en su justa proporción, y al nivel de importancia que Rousseau concede a esta cuestión, en qué medida para éste uno de los primeros males de una comunidad, y quizás su principal veneno, es la ocultación o la no transparencia, junto con la incertidumbre y desconfianza que generan. Se entiende perfectamente, entonces, que Rousseau apenas pudiese soportar que el teatro, como arte por antonomasia 
de la simulación, el disfraz y la mascarada, ocupase un lugar destacado en una ciudad como Ginebra, y que sospechase que tras la propuesta de D'Alembert se hallara la sombra de Voltaire, defensor de una cultura "mundana" de la que sólo cabría esperar, finalmente, que sirviera indirectamente de acicate y casi justificación a la relajación moral, cuando no a la corrupción de las costumbres, verdadera bestia negra del programa moral y social russoniano. Sin embargo, no debemos olvidar que no se trata únicamente de lo que se representa sobre el escenario, por más que éste sea un asunto de enorme importancia. Mucho mayor es la relevancia simbólica del teatro en lo que tiene de inseparable de la comunidad. Cuando Rousseau dice que el teatro aísla a los espectadores, en realidad no se explica con suficiente claridad (ni D'Alembert, en la Carta que le escribe, le comprende). No es lo decisivo que cuando se asiste al teatro cada uno se sitúe de cara a la escena, ignorando a quien tiene sentado a su lado. Ésta es una cuestión menor. En primer lugar, Rousseau contrapone el teatro con un tipo de espectáculos, o más bien de reuniones sociales, clubes y fiestas populares, en los que la relación cara a cara y física, interpersonal, es clara. En estas reuniones, la gente se conoce e interactúa. En el teatro no ocurre de este modo; en la lectura, tampoco, en tanto que se trata de una actividad básicamente solitaria. Sin embargo, en el teatro la gente se congrega, se reúne... para aislarse de inmediato. Sin duda, Rousseau nada podía saber de otras posibilidades, como el cine... No. No es eso lo verdaderamente importante, sino que el "aislamiento" coincide con el placer del olvido y la disipación de la comunidad real y efectiva, siendo ésta la que, sin embargo, debe ser permanentemente cuidada y prestigiada. Nosotros, nuestra realidad, nuestros problemas... Apelar, como hace D'Alembert, al aislamiento del autor no tiene sentido, porque no es a ese aislamiento al que se refiere Rousseau, ni tampoco lo tiene el hacer referencia a la "comunidad" de la Humanidad que el teatro puede conseguir 
poner en escena, porque no se trata tanto de esa Humanidad... Lo que decía D’Alembert es que:

De todos nuestros placeres, el del espectáculo es el que nos relaciona más con los otros hombres, por la imagen que nos presenta de la vida humana y por las impresiones que nos ofrece y nos deja. Un poeta en su entusiasmo, un geómetra en sus profundas meditaciones están más aislados de lo que se está en el teatro. Pero por más que los placeres de la escena nos hicieran perder por un momento el recuerdo de nuestros semejantes, ¿no es ése el efecto natural de la ocupación que nos fija, de toda diversión que nos transporta? ¿Cuántos momentos hay en la vida en los que el hombre más virtuoso olvida a sus compatriotas y a sus amigos sin por ello amarlos menos? Y vos, incluso, señor, ¿no habría renunciado a vivir con los vuestros para poder dedicaros a pensar? (1967-2: 437)

Pero, como digo, no se trataba del autor ni de la humanidad, sino de "nosotros". Es eso lo que está en juego: la comunidad, protestaría Rousseau con una alarma que hoy apenas alcanzaríamos a comprender. Lo decisivo es la implicación interpersonal real, y lo que reiteradamente temía Rousseau es que el exceso de esa diversión "virtual" del teatro trajese consigo, inevitablemente, el olvido o menosprecio de las otras diversiones.

En el fondo, toda la Carta está recorrida por una impresión general de la que se desprende la fina conciencia de Rousseau respecto a la fragilidad y vulnerabilidad de las personas y la comunidad... El problema con el teatro no es separable, en Rousseau, de sus temores más íntimos y de sus propios fantasmas. Retengamos por un momento, por ejemplo, el tratamiento extenso que hace de El misántropo, de Molière (Rousseau, 1994: 43-51). ¡Cómo soportar la visión de toda una comunidad, y la conciencia de esta comunidad respecto a sí misma, viéndose como espectadora, contemplando en escena el inmoralmente irrisorio espectáculo de Alceste, 
es decir, el "misántropo" de Molière, vilipendiado y burlado por ser honesto, veraz, antihipócrita...! ¿No sería descabellado, incluso aberrante, convocar a la comunidad, so pretexto de su formación, para que se le haga reír (Rousseau, 1994: 51, 53, 55) contemplando a un hombre virtuoso cuyo pecado es ser crítico con su entorno social? Rousseau desconfía tanto del teatro, que lo asocia mucho más al divertimento que a la enmienda crítica y moral. No, no se trata de que el teatro promueva la insociabilidad. Lo importante es el tiempo de la comunidad y que no se malgaste... porque no olvidemos, por cierto, que lo que estaba en discusión no era que hubiese representaciones teatrales esporádicas en Ginebra, sino una compañía de teatro estable. En el pensamiento de Rousseau, oscilando extrañamente en muchas ocasiones entre lo huraño y lo sociable, ${ }^{5}$ la comunidad no tiene tiempo que perder y debe evitar las ocasiones (tentadoras) de disipación fuera de su propia verdad.

Rousseau se explaya en su Carta, y acomete argumentos (de tipo social, económico, etc.) contra la propuesta de D'Alembert que con frecuencia distraen enormemente de lo que -a mi juiciodebe ser realmente pensado. Muchos de sus razonamientos nos parecerán hoy un tanto -o muy- extrańos, y algunos extravagantes, cuando no, incluso - no creo ser exagerada-, descabellados. No se trata -o eso sería lo menos relevante- de la vida disoluta de los actores y actrices (tema al que Rousseau en su Carta y D'Alembert en la que envía a Rousseau dedican mucha atención, pues es un lugar común tradicional); tampoco se trata -siquiera en el fondo, aun

\footnotetext{
${ }^{5}$ Nada más comenzar el relato del primero de los paseos de Las ensoñaciones del paseante solitario, dice Rousseau: "Heme aquí, pues, solo en la tierra, sin más hermano, prójimo, amigo ni sociedad que yo mismo. El más sociable y el más amante de los humanos ha sido proscrito de ella por un acuerdo unánime. Han buscado en los refinamientos de su odio qué tormento podía serle más cruel a mi alma sensible y han roto violentamente todos los lazos que me ligaban a ellos. Habría amado a los hombres a pesar de ellos mismos" (1986: 43). Véase la introducción de Francisco Javier Hernández (Rousseau, 1986: 32-33).
} 
cuando esta cuestión es mucho más significativa- del contenido censurable de lo representado en la escena, cuando lejos de resultar edificante para la comunidad, hace el efecto de ser anti-ejemplarizante. Si bien es esto importante, no es lo más importante. Lo decisivo transcurre en un nivel más sintomático y simbólico y -si se me permite- virtual.

Lo que resulta intolerable para Rousseau (y creo que sería esto lo que él mismo finalmente dejaría en pie si hubiera de resumir extremadamente su carta) es la facilidad con la que el teatro favorece la disipación y enmascaramiento de la comunidad y del ser personal. ¿No podría sospecharse de que si la comunidad tomase como modelo al teatro y a los actores (pero no como personas reales y concretas, sino la cualidad misma, la idiosincrasia de una profesión que se arraiga como posibilidad en la condición humana) se iría prestigiando progresivamente el arte en el que éstos son expertos: la falsedad como juego de las apariencias? Para Rousseau está claro:

¿En qué consiste el talento del comediante? Es el arte de fingir, de revestirse de un carácter distinto al suyo, de parecer diferente a como se es, de apasionarse a sangre fría, de decir algo distinto de lo que se piensa con tanta naturalidad como si se pensara de verdad y, en fin, de olvidar su propio lugar a fuerza de ocupar el de otros ¿Qué profesión es la de comediante? Es un oficio en el que el comediante se da en representación por dinero, se somete a las ignominias y afrentas cuyo derecho a hacerle se compra, y pone públicamente en venta su persona [...]. En el fondo, ¿qué idea saca el comediante de su estado? Una mezcla de bajeza, falsedad, orgullo ridículo e indigno envilecimiento que le hacen propio para toda suerte de personajes, salvo el más noble de todos, el del hombre que deja.

Yo sé que el papel de comediante no es el de un bribón que quiera imponerse; que no pretende que se le tome efectivamente por la persona que representa, ni que se le crea afectado por las pasiones 
que imita. Además, al dar esa imitación como lo que es, la vuelve inocente por completo; por eso no le acuso precisamente de ser engañoso, sino de cultivar como único oficio el talento de engañar a los hombres, así como de ejercitarse en hábitos que, no siendo inocentes más que en el teatro, no sirven en ninguna otra parte sino para hacer el mal [...] Los comediantes tienen que se más virtuosos que los demás hombres, si no, son más corrompidos.

El orador y el predicador -podrá decírseme también- se exhiben lo mismo que el comediante. La diferencia es muy grande. Cuando el orador se muestra, es para hablar y no para dar un espectáculo. No se representa más que a sí mismo, no desempeña más que su propio papel, no habla sino en su nombre, no dice o no debe decir más que lo que piensa y, al ser el hombre y el personaje uno mismo, está en su sitio, se encuentra en el caso de cualquier otro ciudadano que cumple las funciones de su estado. Pero un comediante en el escenario, al exponer unos sentimientos distintos de los suyos, al no decir más que lo que se le obliga a decir, al representar a menudo un ser quimérico, se anonada, por decirlo así, se anula con su héroe, y en este olvido del hombre, si de él queda algo, es para ser juguete de los espectadores (1994: 99-101).

A renglón seguido, Rousseau la emprende -si se me permite decirlo así- con las mujeres/actrices. Dejémoslo, pues es suficiente lo que se nos ha dicho en el texto anterior. Estaba "previsto" el rechazo roussoniano hacia el teatro. Lo decisivo no es ya el modo de vida de actores y actrices (la casuística sería enorme), sino el modelo de vida de su profesión, de su cotidiano quehacer. Como ha reconocido David Marshall, el verdadero tema de la Carta no es nada relativo al teatro en cuanto arte, sino la moralidad de los ciudadanos de Ginebra. Yo ańadiría: el psiquismo de esos ciudadanos. Lo peligroso es la proliferación, el contagio del teatro como modelo, y que la propia ciudad se convierta en una especie de enorme teatro, es 
decir, que la ciudad se torne un espectáculo y pierda su "realidad", convirtiéndose en un París en pequeño. Dice Marshall:

Lo que está en juego en la Carta a D'Alembert no es tanto la presencia de un teatro en Ginebra cuanto la posibilidad de Ginebra como teatro. [...] El Teatro amenazaría con transformar a Ginebra en París, para que pasara de ser una versión moderna del estado de naturaleza a ser una sociedad teatral en la que no sólo los actores, sino todos los ciudadanos serían condenados a existir en la relación con los demás. El Teatro se produciría fuera del escenario dibujando espectadores en pose teatral y promocionando el teatro la internalización en la conciencia individual de las relaciones teatrales que, a juicio de Rousseau, caracterizan a la vida social (Marshall, 1988: 141-142, apud. Day, 1997: 148). (La idea original procede de Sennet, 2011).

Así pues, Rousseau no podía soportar ni el prestigio del teatro, arte sistemático de la simulación, ni su potencial proyección prestigiosa en la comunidad. Ésta requiere sobre todo de "realidad", de trabajo y utilidad, de cotidianeidad y concentración, de honestidad y convivencia real, cara a cara... Por eso, en la última parte de la Carta, Rousseau acomete con enorme soltura y elocuencia (pero no es tal nuestro tema) toda una defensa de los otros espectáculos, aquellos en los que la comunidad se involucra verdaderamente y, en comunidad, la comunidad se suelta, se libera y se familiariza con sus propios miembros, incluso se "desfoga" popularmente.

¿Y la novela? Se puede preguntar, desde luego, por su diferencia del teatro. Respecto a la psicología del lector, ¿no es cierto que también se disipa en la irrealidad y compartiendo vidas de otros seres humanos? Efectivamente. Pero la diferencia estriba en que el pueblo no se reúne para aislarse y leer novelas, que ya es un acto más privado, pero sí se reúne para ir al teatro. La comunidad se hace visible para apartarse de la realidad y de su realidad. Y, por 
otra parte, cuando escribe su obra, ¿no es cierto que el autor teatral, más que el novelista, ya prefigura a la comunidad como su receptor? Pero no se trata de esto únicamente. Como recuerda P. L. Day,

Bossuet sugiere que "el espectáculo" es más peligroso que "la lectura”, lo que es muy importante de cara a comprender el ataque de Rousseau contra el Teatro. Bossuet sostiene que "los espectáculos" prestan una inmediatez visceral al proceso de serespectador muy adecuado para inspirar pasiones peligrosas en la audiencia, mientras que la lectura es una actividad solitaria, que permite al lector reflexionar adecuadamente sobre lo que se está leyendo. El lector es mucho menos probable que se vea afectado negativamente por lo que lee que por lo que ve realizado en el escenario, especialmente a la luz del hecho de que el acto de ir al teatro es una experiencia colectiva, en la que, según Bossuet, los espectadores son azotados en un frenesí por los aplausos emotivos de otros. Esta postura, aunque sumamente discutible, sigue en la sociedad moderna también con respeto a los efectos de televisión y películas, cuyos efectos, positivos o negativos, son más inmediatos y viscerales (Marshall, 1988: 141-142, apud. Day, 1997: 147).

La visceralidad podrá llegar hasta la complicidad, y es en esta "auto-alienación” (Marshall, 1988: 145) donde se torna más peligrosa la escena. En efecto, dice Rousseau:

Digámoslo sin rodeos: ¿Quién de nosotros está tan seguro de sí como para soportar la representación de semejante comedia sin ir de a medias en las cosas que allí se interpretan? ¿Quién no estaría un poco molesto si el ratero fuera sorprendido o si fracasara en el intento? ¿Quién no se hace por un momento ratero también al interesarse por él, pues, interesarse por alguien, qué es sino ponerse en su lugar? ¡Hermosa instrucción para la juventud aquella en la que los hombres hechos y derechos tienen dificultades para 
defenderse contra la seducción del vicio! ¿Significa esto que nunca será lícito exponer en el teatro acciones censurables? No; pero la verdad es que, para saber colocar a un bribón en el escenario, es preciso un autor bien decente (1994: 57-58).

El drama del teatro no es otro, en suma, que el de la comunidad y el de la persona, en la medida en que en el teatro pueden compendiarse algunos de los fantasmas (como el de la deshonestidad, la mascarada, la hipocresía, etc.) que tanto obsesionaron a un Rousseau que creía fervientemente en que una comunidad sólo podía aposentarse sobre la transparencia y la convivencia cotidiana y efectiva de sus integrantes.

\section{Drama del teatro, drama de la persona}

Pierre Burgelin tenía razón al decir que "Rousseau se postula como el apóstol de la sinceridad absoluta” (1978: 297). Realmente estaba obsesionado no ya con el teatro como arte, cuanto con su símbolo y su más íntima verdad: la máscara. Es en esta orientación en la que creo que sería necesario rastrear la pista genuina y definitiva para rescatar en nuestra actualidad la problemática russoniana del teatro. En tal sentido, no creo que fuese poco interesante una aproximación a la inquietud de Rousseau a partir del magnífico filme de Ingmar Bergman Persona (1966). No se trata de que sea un filme específica y explícitamente "russoniano", sino que, de hecho, la problemática de la persona en Rousseau es tan intensa, en el contexto general de la crítica cultural de la simulación y el "enmascaramiento", que coincide con planteamientos radicales de Bergman (cuyo conocimiento del mundo teatral era, como es bien sabido, enorme). En realidad, debo confesar que la primera motivación para acercarme a la crítica russoniana al teatro, como se presenta en la Carta, fue justamente el filme de 
Bergman, ${ }^{6}$ porque uno de los dos personajes protagonistas, el interpretado por Liv Ullman -a saber: Elisabet Vogler- representa a una conocida actriz que en cierto momento, durante una representación de Electra, interrumpe su actuación y rompe a reír para, finalmente, enmudecer. A consecuencia de su total enmudecimiento es ingresada para recibir tratamiento psiquiátrico. El otro personaje protagonista de la película corresponde a Alma, la cuidadora que le asignan, interpretado por Bibi Andersson. En el transcurso del filme, pronto la doctora que atiende a Vogler comprende que su enmudecimiento es voluntario y que, por tanto, no está propiamente "enferma". Creo que, en lo esencial, Bergman quiere mostrar a una actriz que se ha quedado "sin alma" debido a que, por su profesión, ha tenido que representar incesantemente las vidas de otros, fingiendo y simulando de continuo. El primer encuentro crítico tiene lugar cuando la enfermera (que manifiesta a Vogler su admiración por los actores y el mundo del teatro) le conecta la radio y una voz, en una emisión radiofónica, dice: “Qué sabes tú de compasión? ¿Qué sabes tú?”, a lo que Vogler reaccciona primero con risas y luego con ira, apagando la radio. En otra escena, a través del televisor, Vogler se asusta de la crudeza y crueldad de la realidad del mundo (Guerra del Vietnam) ${ }^{7}$ -como queriéndosenos dar a entender que el oficio de actriz está muy alejado de esa realidad-. En otro momento, la enfermera, con el consentimiento de Vogler, comienza a leer una carta donde ésta se refiere a asuntos íntimos hasta que, muy perturbada, le impide que prosiga la lectura. El encuentro de la actriz con una doctora, al final de lo que se entiende habría sido su breve estancia en el hospital, es muy significativo; la doctora le dice:

${ }^{6}$ Agradezco a César Moreno (Universidad de Sevilla) esta importante sugerencia, recogida en sus textos sobre el rostro aún -esperemos que por poco tiempo-inéditos.

${ }^{7}$ Volverá a ocurrir más adelante, en el filme, con una fotografía (muy conocida) de prisioneros de Auschwitz. 
¿Crees que no lo entiendo? El sueño imposible de ser. No de parecer, sino de ser. Consciente en cada momento, vigilante. Al mismo tiempo, el sentimiento de vértigo y el deseo constante de, al menos, estar expuesta, de ser analizada, diseccionada, quizás incluso aniquilada. Cada palabra, una mentira; cada gesto, una falsedad; cada sonrisa, una mueca. ¿Suicidarte? ¡Oh, no! Eso es horrible. Tú no harías eso. Pero puedes quedarte inmóvil y en silencio. Por lo menos así no mientes. Puedes encerrarte en ti misma, aislarte. Así no tendrás que desempeñar roles ni poner caras ni falsos gestos. Piensas. Pero, ¿ves? La realidad es atravesada, tu escondite no es hermético. La vida se cuela por todas partes.

Enferma y cuidadora se retiran a una casa de playa, donde viven solitaria y serenamente, en compañía mutua, aunque Vogler sigue sin decir nada. Alma es pura naturalidad, efusividad, entusiasmo y bondad jovial. En cierto momento, le hace saber a Vogler que ella (Alma) ve la vida como un concentrarse firmemente en fines estables: "Imagínate toda tu vida dedicada a algo -le dice a Vogler-. Quiero decir, creyendo en algo, cumpliendo algo, creyendo que tu vida tiene un propósito. A mí me gustan las cosas así”. Alma está preocupada por las experiencias reales, no puramente banales por ficticias (está de más decir que esta firmeza y concentración -por lo demás, tan decisivos en el esquema antropológico y moral de Rousseau- no serían propios de un actor o actriz, tal como los representa Rousseau). Sin embargo, llega el momento más intenso de intimidad del diálogo (minutos 25-32, aproximadamente), en el que Alma cuenta a Vogler un episodio especialmente escabroso de su vida sexual. Acaba llorando y lamentándose de las incoherencias de la vida y por el hecho de ser dos personas a la vez: “¿Puedes ser una y la misma persona a un tiempo? Quiero decir: ¿yo era dos personas?", se pregunta Alma, mientras que Vogler, a su lado, la mira con curiosidad, condescendencia y un leve asomo de ternura. A la mańana siguiente, Alma le muestra la admiración que 
sienta por ella, y le dice: "Creo que me podría convertir en ti, si hiciera un verdadero esfuerzo. Quiero decir por dentro. Tú podrías convertirte en mí así, sin más. Aunque tu alma sería mucho más grande. Rebosaría por todas partes”. Pocas escenas más adelante se observa que Vogler se va recuperando, lo que se muestra en su interés por fotografíar la pedregosa playa que hay junto a la casa en que habitan. Vogler es muy "objetivadora”. El momento de ruptura entre las dos mujeres surge cuando Vogler escribe una carta a su doctora, en la ciudad, en la que se muestra complacida y dice divertirse observando a Alma, de la que cuenta, a grandes trazos, la anécdota de su vida sexual. Indiscreta, Alma lee la hiriente e indiscreta carta de Vogler. Posteriormente le reprochará a Vogler el que, habiéndose ella, Alma, sincerado, haya seguido sumida en su mutismo. Finalmente, le hace dar un grito de exclamación, cuando la amenaza con arrojarle agua hirviendo. La situación de ruptura, que Bergman filma magistralmente, es en torno al minuto cuarenta y cuatro.

¿Debe ser así? [dice Alma]. ¿Es realmente importante no mentir, hablar con un tono de voz verdadero? ¿Se puede vivir sin hablar libremente? Mentir, huir y eludir las cosas. ¿No es mejor dejarse llevar y ser perezoso y descuidado, falso? Quizás serías un poco mejor si te permitieses ser lo que eres. No, tú no lo entiendes. No entiendes lo que estoy diciendo. Eres inaccesible. Dijeron que estabas mentalmente sana, pero tu locura es la peor. Actúas como si estuvieras sana. Lo haces tan bien que todos te creen. Todos excepto yo, porque yo sé lo podrida que estás.

Alma se arrepiente de lo que acaba de decir a Vogler, quien adopta una posición de poder, como si la hubiese ofendido. Alma le pide encarecidamente perdón, pero Vogler se muestra despiadada. Aparece el esposo de Vogler, que es ciego, y Alma hace el papel de ser Vogler, que hará de "guía" de Alma en su fingimiento. Bergman 
utilizará, en adelante, con gran frecuencia y eficacia enormes primeros planos, sobre todo de Vogler, en los que se muestra la dureza de su rostro/máscara. Cuando Alma ya no lo soporte más dirá que se avergüenza, y más: “¡Estoy fría, podrida e indiferente! Todo son mentiras e imitaciones. ¡Todo!”. Adelante, llegamos a conocer el secreto de Vogler. En el caso de Alma, abortó a raíz de aquella aventura sexual juvenil a que antes me referí, pero no se vio obligada a ser una "mala madre". De hecho, se siente arrepentida. El caso de Vogler fue diferente. Actuó como si pudiera ser y fuese una buena madre, pero tras varios intentos de abortar, su hijo nació, ganándose el odio de su madre porque, además, su amor al teatro le hacía muy difícil compaginarlo con las exigencias de la maternidad. Quiso que su hijo muriese, pero, en lugar de eso, el niño quería cada vez más a su madre. En una escena ya casi final, tremendamente dramática, Vogler muerde a Alma en la muñeca, como si quisiera chuparle la sangre, a lo que responde Alma con sucesivas bofetadas, porque antes ha dejado claro, en la gran rivalidad que se ha abierto entre las dos mujeres, que ella, Alma, no quería ser como Vogler. Bergman deja un final abierto en el que lo único cierto es la ruptura de la comunidad y amistad de las dos mujeres.

Creo que un argumento como éste nos impide olvidar el nivel de preocupación que Rousseau sentía no ya por el teatro, sino por lo que quizás tendría él mismo a bien denominar la "teatralidad de la persona y de la comunidad", y no como si se tratase de un juego, sino como una posibilidad tremendamente inquietante. El teatro es sólo la punta de iceberg de un asunto mucho más grave, como es esa suerte de alienación, frialdad, indiferencia, dominio del parecer sobre el ser que los comediantes profesionalizan... potenciando una tendencia humana ya demasiado común como para prestigiarla irresponsablemente, atizando la decadencia cultural de los valores, de acuerdo con el punto de vista de Rousseau. 


\section{El sueño de la transparencia se torna pesadilla}

Tenemos muchos más recursos en nuestra tradición cultural para asumir críticamente la relación entre ser y parecer que para concederle alegremente nuestro beneplácito. La posición contracultural russoniana conecta con algo que se parece a una fantasmagorización del teatro tal que éste concentraría en sí, adornándola, prestigiándola, haciéndola compartible, la energía maligna de la victoria del parecer sobre el ser. Cualquiera que conociese a Rousseau, sólo a partir de sus Discursos, habría sabido predecir perfectamente su reacción. En todo caso -y en tal sentido quisiera avanzar- habría sido interesante confrontar al pensador con la posibilidad de una radicalización en la sociedad de lo contrario de la mascarada teatral comunitaria, es decir, con una sociedad en la que las vidas y, casi se diría que los pensamientos, fuesen transparentes... Es en los mejores sueños de Rousseau, más que en sus pesadillas, donde aparece el ideal de la transparencia. Y sin embargo, ¿̨no se arriesga su "humanismo de la transparencia" por mor de una enorme ingenuidad, al concebir la transparencia bajo los ideales de la sinceridad y de la comunidad -justamente a mediados del XVIII-, y no bajo los modelos del poder y del espectáculo? Rousseau confiaba tanto en la transparencia, que no temía la visibilidad de ciertos malos comportamientos, jcon tal de que no se ocultasen!, ${ }^{8}$ e incluso llegaba a defender el cotilleo, por una exigencia de presión social. ${ }^{9}$

\footnotetext{
${ }^{8}$ Por ejemplo, los malos comportamientos que se infiriesen de una cierta naturalidad, espontaneidad, rusticidad, etc., y que la comunidad pudiese asumir (Rousseau, por nombrar un caso, se muestra condescendiente con la ebriedad, cierto nivel moderado de erotismo en las fiestas populares, la rusticidad de palabras malsonantes, etc.).

${ }^{9}$ He estudiado con detenimiento la función social, como servicio del poder, del cotilleo en Séneca y la crítica al cotilleo en Plutarco (véase, respectivamente, Mingo, 2011 y Mingo, 2012).
} 
Tal es nuestra pregunta, casi final: ¿en qué términos habría podido redactar Jean-Jacques Rousseau, hoy, una nueva Carta sobre los espectáculos, dirigida a los mil y un medios de comunicación que nos envuelven? Más concretamente, ¿qué opinión le habría merecido, ya que se había mostrado tan favorable a la transparencia, el espectáculo de personas exhibiendo en público -lo diremos con una expresión muy castellana- sus "trapos sucios", sus vidas denigradas, degradadas o desdichadas, y que se les pagase por ello, sirviendo de entretenimiento a un "personal" al que hay que hacer reír y "empatizar" a toda costa? ¿No podría culminar de este modo, con bombo y platillo, no menos que truculentamente, y completamente deformada, aquella aspiración russoniana de la transparencia - por el intermedio, lógicamente, del Gran Hermano orwelliano-? Y en otro sentido, ¿̇no tendría razón Richard Sennet al mostrar hasta qué punto la transparencia puede convertirse en destructiva? ${ }^{10}$ Para Rousseau todo fue desde el principio muy claro (quizás demasiado claro):

Si hubiese podido escoger el lugar de mi nacimiento, hubiese escogido una sociedad de una anchura limitada por la extensión de las facultades humanas, es decir, por la posibilidad de ser bien gobernados [...]; un Estado en el que todos los particulares se conociesen entre sí y ni las maniobras del vicio ni la modestia de la virtud hubiesen podido ocultarse a las miradas y al juicio del público, y en el cual esa dulce costumbre de verse y conocerse

\footnotetext{
${ }^{10}$ Retornando a Persona, de Bergman, habría que observar que los problemas de la ínfima e íntima comunidad que forman en su retiro costero la actriz Vogler y la enfermera Alma surgen a raíz, primero, de la no-reciprocidad, pues sólo Alma se confiesa (para estimular a Vogler a hablar), mientras que Vogler permanece en su absoluto mutismo; y segundo, de lo que luego la propia Alma llamará su "exhibicionismo total", por haber contado a Vogler aquel episodio escabroso de su vida sexual, y de la indiscreción "cotilla” de Vogler, contándole a su doctora el incidente vivido por la enfermera. A partir de ese momento la comunidad se rompe.
} 
convirtiese el amor a la patria en amor a los ciudadanos, mejor que en amor de la tierra (Rousseau, 1977: 128). ${ }^{11}$

Rousseau replicaría que un gran mal (como el de los reality y talkshows) no quitaría un ápice del otro mal, el del teatro. Respondería que, en cierto modo, en estos espectáculos se enarbola la antihipocresía, la honestidad... aunque sean pagadas (Mingo, 2011-b) ${ }^{12}$ y a costa del desprestigio de, al menos, ciertos miembros de la comunidad, a los que se podría utilizar para un ejemplar escarnio público.

Por otra parte, la crítica a esta práctica de la transparencia no podría ir en demérito de su valor general, aunque sí serviría para controlar sus malversaciones y abusos. Como dije antes, a Rousseau no le parecía mal el cotilleo (Rousseau, 1994: 132-133) ni esa transparencia propia de una comunidad pequeńa en la que todos saben de todos porque el vivir a la vista de todos se ha convertido en práctica cotidiana. Aunque se alimenten del no vivir cada uno su propia vida, sin embargo, esta suave "alienación" hace que se refuercen los lazos de la comunidad como -solemos decir- "patio de vecinos". Las "cotorras" cumplen este papel un tanto "sucio", escasamente digno, pero necesario de hecho. Eso sí, es imprescindible que no haya mentira ni difamación (lo que Rousseau considera que es el caso, tratándose de las mujeres/cotorras ginebrinas de su

${ }^{11}$ Las confesiones de Rousseau equivaldrían a su intento de poner su vida al desnudo, delante de todos... El estudio de Starobinski es imprescindible en este sentido.

${ }^{12}$ Un ejemplo extraordinario de ello es el programa El juego de tu vida, o, como se titula en otros países, The Moment of Truth. La primera edición fue colombiana. El concurso consiste en que a las preguntas cada vez más comprometedoras que se van haciendo al concursante (de acuerdo con las cuales sube la cuantía monetaria del premio), éste tiene que decir la verdad (a la que previamente, se supone, la dirección del programa ha accedido después de someter al concursante a una enorme cantidad de preguntas en una "máquina de la verdad"). Si miente, pierde. Lo que se recompensa es una sinceridad radical que se presenta $-\mathrm{y}$ es, de hecho- absolutamente impúdica. 
época). ¿Por qué, así pues, no le importaba a Rousseau el cotilleo, en lo que tiene de estar pendientes de los asuntos de los otros, y sí el teatro? Porque el primero hace comunidad de forma muy intensa, concentradamente, con una intensidad que incluso puede llegar a ser insoportable, además de ser un apoyo importante para el poder que la misma comunidad ejerce sobre sus miembros; mientras que el teatro es mucho más disipativo. La gente se reúne, es cierto, pero para dispersarse en medio de la escena... Así que la crítica al teatro no depende únicamente de la mascarada como un vivir la vida de otros, sino de la mascarada como disipación.

Desde siempre se reconoció en el teatro el poder no ya sólo de representar, sino de incitar y de proponer ingente material de representaciones, escenas y modelos a la mimesis. Rousseau penetró más hacia el interior, porque fue extremadamente sensible al drama del ser personal, al debate entre el querer ser auténticamente uno mismo, casi a toda costa, y las posibilidades que la cultura brinda para fingirse uno viviendo otras vidas y creerse otro. Lo que le preocupaba realmente no era sólo el contenido de lo representado en el teatro, sino la psicología del actor y del espectador y sus implicaciones morales.

No cabe duda de que desde mediados del siglo XVIII hasta la actualidad hemos ganado una experiencia de la que se carecía en la época de Rousseau, y hemos constatado el poder general de la ficción, que, por otra parte, se ha banalizado enormemente, bajo el efecto de su multiplicación y rutina. Puede ser que hayamos bajado mucho la guardia respecto a la importancia que concedemos a, en general, los espectáculos, pero sobre todo a los espectáculos en el horizonte de la representación y la escena, que tan increíblemente se han multiplicado cuantitativa y cualitativamente. Hemos focalizado y localizado tanto la ficción como ficción, que creemos poder dominar el trato con ella, manteniéndola justamente en la zona de la escena, el filme o el juego... Pero quizás hemos sido demasiado 
optimistas con la ficción, tanto como lo fue Rousseau con la transparencia. Entretanto, no creo que pueda dudarse de que la comunidad ha decaído por completo en nuestras sociedades abstractas y deshumanizadas, dispersas y disipadas. Quizá las inquietudes de Rousseau hoy puedan parecernos exageradas, llenas de injustificados fantasmas, con los que hubo de debatirse un pensador progresivamente alejado no ya del "progreso", sino, como él mismo decía, de la sociedad y compañía de los otros hombres. Y sin embargo, nada garantiza que nuestra banalización del espectáculo, en medio de su inmensa abundancia, no haya contribuido a nuestra íntima despersonalización, uno de los núcleos más recónditos de nuestra crisis de civilización.

\section{Bibliografía}

Burgelin, P., 1978, La philosophie de l'existence de J.-J. Rousseau, Ginebra, Slatkine Reprints.

D’Alembert, 1967, "Description abrégée du Gouvernement de Genève", en Oèuvres complètes de D'Alembert, vol. IV, $1^{a}$ parte, Ginebra, Slatkine Reprints, pp. 411-422.

D'Alembert, 1967-2, “Lettre à J. J. Rousseau, citoyen de Genève”, en Oeuvres de D'Alembert, vol. IV, $1^{\text {a }}$ parte, Ginebra, Slatkine Reprints, pp. $432-458$.

Day, P. L., 1997, “Jean-Jacques Rousseau's Lettre à D'Alembert sur les spectacles: A Philosophical Aberration or a Moral Imperative?", en Rousseau on Arts and Politics. Autour de la Lettre à d'Alembert, editado por Melissa Butler, Ottawa, Pensee Libre, 6, North American Association for the Study of Jean-Jacques Rousseau, pp. 141-150.

Gouhier, H., 1983, Rousseau et Voltaire. Portraits dans deux miroirs, París, Vrin.

Marshall, D., 1988, The Surprising Effects of Sympathy: Marivaux, 
Diderot, Rousseau. and Mary Shelley, Chicago y Londres, The University of Chicago Press.

Mingo, Alicia Ma de, 2012, "Conoceos a vosotros mismos. Un estudio sobre la relevancia democrática del fisgoneo, a partir de Plutarco", en Ideas y Valores. Revista Colombiana de Filosofía, LXI, 150, Bogotá. ,2011, "Vivir en público y paideía privada en las Cartas a Lucilio de L. A. Séneca”, en Areté. Revista de Filosofía (Lima, PUCP), XXIII, 2, Lima, pp. 277-302.

, 2011-b, "A la vista de todos. Democracia panóptica y sociedad del espectáculo", en La ética de la comunicación a comienzos del $S$. XXI, (ed., J. C. Suárez), Sevilla, Eduforma, pp. 342-354.

Rousseau, J. J., 1997, Las confesiones, (ed. M. Armiño), Madrid, Alianza Editorial.

, 1994, Carta a D'Alembert sobre los espectáculos, (ed. J. R. Carracedo y trad. y notas de Quintín Calle Carabias), Madrid, Tecnos.

, 1986, Las ensoñaciones del paseante solitario, (ed. Francisco Javier Hernández), Madrid, Cátedra.

, 1977, Discursos a la Academia de Dijon, (introd., trad. y notas de Antonio Pintor Ramos), Salamanca, Ediciones Paulinas.

, 1977-2, "Respuesta de Rousseau" [a Voltaire], en Rousseau, J.-J, 1977, pp. 276-279.

Sennet, R., 2011, El declive del hombre público, Barcelona, Península.

Starobinski, J., 1983, Jean-Jacques Rousseau. La transparencia y el obstáculo, Madrid, Taurus.

Voltaire, 1977, “Carta a Rousseau” (30-VIII-1755), en Rousseau. J.-J., 1977, pp. 273-276. 